\title{
Investigation of parametric optimisation for the extraction of rice bran oil with the aid of ultrasound and its synthesis to biodiesel
}

\author{
Akash Pratim Bora $^{{ }^{*}}$, Sriya Naik ${ }^{I}$, Krishna Sandilya Durbha ${ }^{1}$ \\ ${ }^{1}$ Department of Chemical Engineering, Indian Institute of Technology (Indian School of Mines), Dhanbad, India
}

\begin{abstract}
Improvisation of the biodiesel production using low-cost feedstock and the process optimisation is the perfect measure for the mitigation of high cost associated with the production process. In this current study, we are focussing on the extraction of rice bran oil (RBO) which is mainly considered underutilised waste material for the synthesis of biodiesel. Solvent extraction of RBO was performed with the aid of ultrasound and the study of various process parameters were exhibited using design of experiment by Taguchi model. The highest extraction efficiency was obtained at $\mathrm{S} / \mathrm{R}$ ratio: $4: 1(\mathrm{ml} / \mathrm{g})$, Agitation speed: $150(\mathrm{rpm})$, Agitation time: 60 (min), Size range: 427.5 (micron), Sonication time (min): 15 (min) and Power level: $70(\mathrm{KW})$. It was observed that the ultrasound-assisted extraction produced better quality oil than the extraction performed by conventional Soxhlet. Secondly, the esterification was performed using sulphuric acid as the acid catalyst and parametric optimization was performed for the enhancement of biodiesel yield using L9 orthogonal array. The key factors viz. agitation speed of 1000 $\mathrm{rpm}$, methanol to oil ratio (M/O) of 10 :1 and reaction temperature of $60{ }^{\circ} \mathrm{C}$; were found to be favourable for the attainment of the maximum yield of biodiesel.
\end{abstract}

\section{Introduction}

The increase in the consumption of the conventional fossil fuel along with the proclivity of variation in oil prices in the international market concomitance with the environmental regulation impetus the researchers towards alternate sources of energy [1].The alternate sources of energy are primarily based on the usage of wind, hydro, solar and plant biomass [2, 3]. Renewable bio-fuels mainly obtained from the plant based biomass are deemed to be the fourth source of energy in the global scenario utilized for thermal and electric power generation $[4,5]$. It is approximated that by the year 2030 the renewable bio-fuels would constituted around $4-7 \%$ of the total energy consumption globally [6]. The most popular bio-fuel is the biodiesel owing to its nontoxicity, biodegradability, lower emission profile and exquisite lubricity [7]. Biodiesel can be characterized as the blend of fatty acid alkyl esters produced form the transesterification/esterification of triglyceride in the oil with the lower chain alcohols [8]. The raw materials for the synthesis of biodiesel comprise of various edible and non edible vegetable oil and it contributes approximately $80 \%$ of the production cost [9]. Additionally, employment of vegetable as the primary raw materials facilitates the depletion of fresh water resources and arable land [10]. However, oil derived from waste biomass, waste cooking oil, and yellow grease which are associated with low cost and readily accessible; could become the potential feedstock for efficient production of biodiesel [11]. In this scenario rice bran oil (RBO) could stand as a favourable alternative which is an inexpensive co-product of rice] milling process with 15$23 \%$ oil content [12]. But the extraction of RBO from the bran is inhibited by its high ash contents, FFA, unsaponifiable components and polar lipids [13]. Previous literature suggested a plethora of extraction methods viz. solvent extraction, cold press extraction, extraction using super critical fluid and microwave assisted extraction [14]. However, irrespective of having some pros and cons, these processes restrained form commercialization because of lower sustainability in thermal and pressure stress, higher requirement of solvent and extraction time $[15,16]$. Although Solvent extraction is widely exploited it needs higher extraction time and furthermore usage of organic solvent in large quantities is also prohibited and harmful to the environment. For these reasons, ultrasound assisted extraction (UAE) which is an inexpensive and simple intensification tool can be employed.

Recent Studies reported that extraction efficiency can be increased effectively by using ultrasonic irradiation [17]. Ultrasonic waves can destroy the walls of cell membranes allowing solvent to breach into the interior solid and letting the interior product free. This resulted in increment of the contact surface area and enhancement of mass transfer between solvent and solid particles. Therefore, by using ultrasound, extraction time had been shortened and due to increase in contact area, solvent consumption had been reduced [18].Transesterification is the widely used method for the synthesis of biodiesel 
from the oil using both homogeneous and heterogeneous catalyst [19]. Different operating conditions viz. temperature of the reaction, catalyst type and concentration, solvent to oil ratio plays an imperative role in the biodiesel production [20]. Various researchers reported of using homogeneous catalyst for the transesterification reaction owing to their higher efficiency, lesser reaction time and ease of separation as compared to that of the heterogeneous catalyst [21, 22]. The most common method of using alkali catalysed transesterification limited its application in the high amount of free fatty acid (FFA) and moisture containing feedstock materials [23]. RBO contains approximately $80 \%$ FFA content primarily based on the storage conditions thus restrain from the synthesis to biodiesel via alkali catalysed reaction [24]. Hence, an acid catalyst can be employed for the simultaneous esterification and transesterification reaction which are insusceptible to the high amount of moisture and FFAs [25].

Not many in the open literature reported about the ultrasound-assisted extraction of oil using hexane as an organic solvent and the optimisation of the process parameters using design of experiment procedure. The aim of this study was to govern the most effective factor affecting the yield of RBO with ultrasound assisted extraction method using design of Taguchi statistical approach. The later part of the work constitutes the synthesis to biodiesel using sulphuric acid as the homogeneous catalyst and also formulates the parametric optimisation using Taguchi model.

\section{Experimental works}

\subsection{Materials}

Hexane was used as the organic solvent for the extraction process obtained from Merck, India. Full fat rice bran was collected from the local rice mills near Govindpur, Dhanbad (Jharkhand, India). Fresh rice bran was collected over a series of screens and the respective masses were stored in plastic bags. These plastic bags were stored in refrigerator at $0^{\circ} \mathrm{C}$ to control the growth of FFA. Sulphuric acid (98\%) used as the catalyst in the transesterification was purchased from RANKEM, India.

\subsection{Extraction of rice bran oil}

RBO was extracted from rice bran in a Soxhlet apparatus by varying different parameters like solvent to rice bran ratio, agitation speed, time of extraction, size range of bran particles, sonication time and ultrasonic power level. Different size ranges of bran particles have been collected by sieve analysis and have been kept in plastic bags separately at $0^{\circ} \mathrm{C}$. After the operation of cycles in the Soxhlet, hexane was recycled using a distillation apparatus. For the UAE experiment, an ultrasonic bath tank which was made of cavitation-resistant stainless steel withstainless steel casing (Ultrasonic Cleaning Units, (C) Elma GmbH \& Co KG) has been used. The desired size range of bran particles have been mixed in 1 $\mathrm{L}$ of water contained in a glass beaker. The impeller was inserted directly into the beaker for uniform mechanical agitation. After performing the sonication for the desired time, the sample has been taken out from the bath and dried it completely in the hot air oven. After drying, the proceedure for extraction was repeated as mentioned earlier.

The percentage of oil extractability were calculated using the following equation (1)

$\%$ Oil extractability $=\frac{\text { weight of oil extracted }(g)}{\text { weight of initial rice bran }(g)} * 100$

\subsection{Design of experiments by L25 orthogonal array approach}

Taguchi method has been used extensively in optimizing several engineering and industrial problems. As for as the conventional method is concerned, it unnecessarily increased the number of runs involving variation of single parameters keeping all other parameters constant throughout the process. Due to increment in runs, cost of performing them will also increase. To avoid these complexities, Several statistical concepts came into the picture. These concepts have been used in optimizing the chemical process and quantify the final product quality. Taguchi method was primarily introduced to examine the effect of individual factors on the main objective function. This method has been also used to investigate the most significant factor among all which was going to affect the most to the main objective function. Taguchi method primarily focuses on two things: The first one is to estimate the deviation from the desired function and the second one is to provide the best set of experimental conditions which was most economical. It provides a fewer and probably the best set of minimal experimental runs [26].

The extraction experiment was performed by the L25orthogonal array matrix designed by Taguchi method (Design expert, Stat-Ease, USA) and elucidated in Table 1.

Table 1. Experimental design matrix developed by Taguchi method (UAE)

\begin{tabular}{|l|l|l|l|l|l|l|}
\hline $\mathbf{R} / \mathbf{S}$ & AS & ET & SR & ST & PL & OY \\
\hline $1: 7$ & 350 & 60 & 125 & 75 & 90 & 17.782 \\
\hline $1: 3$ & 450 & 120 & 605 & 60 & 90 & 16.258 \\
\hline $1: 4$ & 250 & 90 & 605 & 75 & 60 & 17.965 \\
\hline $1: 4$ & 450 & 150 & 125 & 30 & 80 & 17.025 \\
\hline $1: 6$ & 450 & 60 & 855 & 45 & 60 & 18.784 \\
\hline
\end{tabular}




\begin{tabular}{|c|c|c|c|c|c|c|}
\hline $1: 5$ & 150 & 90 & 855 & 30 & 90 & 18.01 \\
\hline $1: 5$ & 250 & 120 & 125 & 45 & 100 & 14.148 \\
\hline $1: 4$ & 350 & 120 & 855 & 15 & 70 & 15.065 \\
\hline $1: 7$ & 450 & 90 & 302.5 & 15 & 100 & 19.245 \\
\hline $1: 3$ & 550 & 150 & 855 & 75 & 100 & 18.896 \\
\hline $1: 4$ & 550 & 30 & 302.5 & 45 & 90 & 19.704 \\
\hline $1: 3$ & 250 & 60 & 302.5 & 30 & 70 & 21.796 \\
\hline $1: 3$ & 350 & 90 & 427.5 & 45 & 80 & 21.825 \\
\hline $1: 5$ & 550 & 60 & 605 & 15 & 80 & 18.741 \\
\hline $1: 3$ & 150 & 30 & 125 & 15 & 60 & 13.291 \\
\hline $1: 7$ & 250 & 30 & 855 & 60 & 80 & 18.35 \\
\hline $1: 6$ & 550 & 90 & 125 & 60 & 70 & 22.16 \\
\hline $1: 5$ & 450 & 30 & 427.5 & 75 & 70 & 20.704 \\
\hline $1: 7$ & 150 & 150 & 605 & 45 & 70 & 21.068 \\
\hline $1: 6$ & 150 & 120 & 302.5 & 75 & 80 & 15.972 \\
\hline $1: 4$ & 150 & 60 & 427.5 & 60 & 100 & 22.861 \\
\hline $1: 6$ & 250 & 150 & 427.5 & 15 & 90 & 18.52 \\
\hline $1: 6$ & 350 & 30 & 605 & 30 & 100 & 21.436 \\
\hline $1: 7$ & 550 & 120 & 427.5 & 30 & 60 & 17.792 \\
\hline $1: 5$ & 350 & 150 & 302.5 & 60 & 60 & 11.278 \\
\hline
\end{tabular}

Where, AS: Agitation speed; ET: Extraction time; SR: Size range; ST: Sonication time; PL: Power level; OY: Oil yield (\%)

In this study six parameters have been choosen up to five levels and range of choosen levels have been summarized in Table 2.

Table 2. Parameters chosen at five levels for L25 design (UAE)

\begin{tabular}{|l|l|l|l|l|l|}
\hline Parameters & $\mathbf{1}$ & $\mathbf{2}$ & $\mathbf{3}$ & $\mathbf{4}$ & $\mathbf{5}$ \\
\hline R/S & $1: 3$ & $1: 4$ & $1: 5$ & $1: 6$ & $1: 7$ \\
\hline AS & 150 & 250 & 350 & 450 & 550 \\
\hline ET & 30 & 60 & 90 & 120 & 150 \\
\hline SR & 125 & 302.5 & 427.5 & 605 & 855 \\
\hline ST & 15 & 30 & 45 & 60 & 75 \\
\hline PL & 60 & 70 & 80 & 90 & 100 \\
\hline
\end{tabular}

\subsection{Analysis}

The completion of the esterification reaction can be signified by the rate of conversion of FFA or the acid value. The FFA value w0as determined by the standard EN 14104 method [27]. The properties of the RBO estimated by standard ASTM methods are presented in Table 3.

Table 3 Physicochemical properties of the RBO

\begin{tabular}{|c|c|}
\hline Property & RBO \\
\hline Acid value $(\mathrm{mg} \mathrm{KOH} / \mathrm{g})$ & 5.7 \\
\hline Free fatty acid content $(\%)$ & 2.85 \\
\hline Specific gravity at $31^{\circ} \mathrm{C}$ & 0.918 \\
\hline $\mathrm{K}$ viscosity $(\mathrm{cSt})$ & 28.70 \\
\hline
\end{tabular}

\subsection{Esterification of RBO into biodiesel}

The esterification of RBO was carried out in a three necked round bottom flask endowed with a thermometer on one side and the other side was connected with a helical tube reflux condenser to recycle the evaporative methanol. The catlyst was added via the third neck to the reaction mixture of methanol and $\mathrm{RBO}$ after the attianment of the desired temperature. The reaction mixture was heated to the desired temperature with the help of a magnetic stirrer hot palte endowed with a temperature controller. The reaction was conducted for one hour with the reaction parameters set by the design matrix postulated by L9 orthogonal array, specified in Table 4.

Table 4 Experimental design matrix for esterification

\begin{tabular}{|c|c|c|c|c|}
\hline $\mathbf{M} / \mathbf{O}$ & $\mathbf{C ~ L}$ & $\mathbf{T}$ & $\mathbf{A ~ S}$ & $\mathbf{F C}$ \\
\hline $8: 1$ & 2.5 & 70 & 800 & 87.2 \\
\hline $12: 1$ & 1.5 & 60 & 800 & 85 \\
\hline $8: 1$ & 3.5 & 50 & 1000 & 90 \\
\hline $10: 1$ & 2.5 & 50 & 1000 & 95.8 \\
\hline $10: 1$ & 3.5 & 70 & 600 & 89 \\
\hline $8: 1$ & 1.5 & 50 & 600 & 81.5 \\
\hline $12: 1$ & 2.5 & 50 & 1000 & 86 \\
\hline $12: 1$ & 3.5 & 60 & 600 & 83 \\
\hline $10: 1$ & 2.5 & 70 & 1000 & 97.6 \\
\hline
\end{tabular}

Where,CL: Catalyst loading; T: Tempeartre; AS: Agitation speed; FC: FFA conversion (\%)

The four parameters viz. reaction temperature, methanol to oil ratio, catalyst loading and agaitation speed varied at three levels specified in Table $\mathbf{5}$. 
Table 5 The parameters chosen at three levels for DOE by L9 orthogonal array

\begin{tabular}{|c|c|c|c|}
\hline \multirow{2}{*}{ Parameters } & \multicolumn{3}{|c|}{ Levels } \\
\cline { 2 - 4 } & $\mathbf{1}$ & $\mathbf{2}$ & $\mathbf{3}$ \\
\hline $\mathrm{M} / \mathrm{O}$ & $8: 1$ & $10: 1$ & $12: 1$ \\
\hline $\mathrm{CL}$ & 1.5 & 2.5 & 3.5 \\
\hline $\mathrm{T}$ & 50 & 60 & 70 \\
\hline $\mathrm{AS}$ & 600 & 800 & 1000 \\
\hline
\end{tabular}

For the pre processing section the raction mixture was transferred into a separting funnel after the completion of the reaction. The mixture was then kept for 5-6 hrs and then separated out into two phase viz. oil rich and aqueous one. The oil was decated into a beaker and preserved for further analysis (ASTM standards) while the water was drained out of the separator. The conversion of the FFA into fatty cid methyl esters (FAME) was estimated by the following equation (2)

$C_{\text {ester } \%}=\frac{C_{i}-C_{t}}{C_{t}} \times 100$

Where $C_{i}$ is the initial acid value of the sample and $C_{t}$ is the acid value measured at time $t$.

\subsection{Statistical analysis of the process by ANOVA}

The most important feature of adopting Taguchi method is to determine signal to noise ratio (SNR) which was obtained by following the orthogonal array matrix. It tells us about the order of performance of each parameter i.e. in which order individual parameters are going to affect the performance characteristic (yield of oil and biodiesel). It doesn't tell about the percentage contribution of each parameter on the performance characteristic(oil yield). For this information, Analysis of variance (ANOVA) apporach can be used effectively. Contribution factor (equation 3) can be calculated by using the ratio of sum of squareof that particular parameter to the overall sum of square of the the model.

Contribution factor $=\frac{S S_{f}}{S S_{T}} \times 100$

Where, $\mathrm{SS}_{\mathrm{f}}$ and $\mathrm{SS}_{\mathrm{T}}$ are the sums of squares of that particular parameterand the total sum of squaresof all the parameters of that specific model respectively. The regression analysis of the given set of experiments was done and an model equation was developed. To testify the valdiation of the model equation, experiments were performed at suggested optimal conditions in triplicates and compared with the predicted responses.

\section{Results and discussion}

\subsection{Statiscal analysis}

\subsubsection{Extraction of RBO}

The extraction of RBO were performed according to the design matrix formulated by the L 25 orthogonal array matrix and corresponding result (oil yield) of the each experimental run were fed to analyse the data. Table 6 represents the analysis of variance (ANOVA) for UAE around the mean of the objective function statistically.

Table 6.variance analysis model and process parameters (UAE)

\begin{tabular}{|l|l|l|l|l|l|l|}
\hline Source & $\begin{array}{l}\text { Sum of } \\
\text { squares }\end{array}$ & Df & $\begin{array}{l}\text { Mean } \\
\text { square }\end{array}$ & $\begin{array}{l}\text { F } \\
\text { value }\end{array}$ & $\begin{array}{l}\text { P } \\
\text { value }\end{array}$ & $\begin{array}{l}\text { Signif } \\
\text { icant }\end{array}$ \\
\hline Model & 174.86 & 16 & 10.93 & 3.30 & 0.045 & \\
\hline A- R/S & 22.39 & 4 & 5.60 & 1.69 & 0.243 & \\
\hline C- ET & 61.46 & 4 & 15.37 & 4.65 & 0.031 & \\
\hline D- PS & 37.58 & 4 & 9.39 & 2.84 & 0.097 & \\
\hline F- PL & 53.43 & 4 & 13.36 & 4.04 & 0.044 & \\
\hline Residual & 26.45 & 8 & 3.31 & & & \\
\hline Cor total & 201.31 & 24 & & & & \\
\hline
\end{tabular}

Study of ANOVA contains some of the vital tests like Fischer's statistical test (F-value), likelihood of obtaining F-value and sum of squares to evaluate the significance level of an individual factor. Larger F-value assumed to be more significant. In this study, analysis of variance (ANOVA) for UAE has been analysed at a level of significance $\alpha=5 \%$ (confidence level of 95\%). Significance level of an individual factor is determined by comparing the $\mathrm{P}$ values. The parameter which was having $\mathrm{P}$ value less than 0.05 assumed to be the most significant parameter. The data analysed by the statistical method recommended using 3FI model for the optimisation of the process. The obtained value of sum of squares and $\mathrm{F}$ value for the chosen model are 174.86 and 3.30 respectively. The model $F$ value of 3.30 signifies the validity of the model and there is only $4.58 \%$ chance that an $\mathrm{F}$ value of this large could occur due to noise. It can be depicted from the adequate signal of the model that it is effective in optimising the extraction of UAE assisted RBO. The ANOVA study also inferred that the four parameters are significant to the yield of RBO. Out of all the parameters extraction time has the most prominent effect with an $\mathrm{F}$ value of 4.65 followed by ultrasonic power level having the value of 4.04. The result obtained from ANOVA study can be validated by estimation of the contribution factor for each individual parameter calculated by using equation (3). 
It is depicted form the result that the extraction time has the most significant effect on the RBO yield with a contribution factor of $35.43 \%$ and ultrasonic power level stood $2^{\text {nd }}$ with a contribution factor of $30.55 \%$. It is then followed by particle size and lastly the R/S (rice bran/ Solvent, $\mathrm{g} / \mathrm{ml}$ ) with contribution factor of $21.49 \%$ and $12.80 \%$ respectively. The two factors viz. sonication time and agitation speed are found to be insignificant within their chosen range and hence they are not included in the statistical analysis. The value correlation coefficient like $\mathrm{R}^{2}$ was estimated form the ANOVA study and found to be 0.8686 which interpreted the fit of the experimental data in the model. A slightly lower $\mathrm{R}^{2}$ value implies that the overall mean may be a better predictor of the response than the current model. A higher order model may be preferable in this case. Adequate precision measures the signal to noise ratio and having the value of 7.215 indicates an adequate signal which implies the model can be used to navigate the design space.

\subsubsection{Esterification of oil}

The esterification experiment were performed according to the design matrix formulated by the L9 orthogonal array given in Table 4. The $\mathrm{F}$ value obtained from the ANOVA is 103.56 which implies the significant of the model. It is also interpreted from the model that there stood only $0.96 \%$ channe that the Fvalue higher than that occur due to noise. The three parameters are found to be more significant on the process of esterification, summarised in Table 7.

Table 7 ANOV study for FFA conversion

\begin{tabular}{|l|l|l|l|l|l|l|}
\hline Source & $\begin{array}{l}\text { Sum of } \\
\text { squares }\end{array}$ & $\begin{array}{l}\text { Df } \\
\text { Mea } \\
\text { squa } \\
\text { re }\end{array}$ & $\begin{array}{l}\mathbf{F} \\
\text { value }\end{array}$ & $\begin{array}{l}\text { P } \\
\text { value }\end{array}$ & $\begin{array}{l}\text { Signifi } \\
\text { cant }\end{array}$ \\
\hline Model & 237.06 & 6 & 39.5 & 103.56 & 0.0096 & \\
\hline A1-M/O & 51.47 & 2 & 25.7 & 67.46 & 0.0146 & \\
\hline C1- T & 10.24 & 2 & 5.12 & 13.42 & 0.0693 & \\
\hline D1-AS & 79.54 & 2 & 39.7 & 104.25 & 0.0095 & \\
\hline Residual & 0.7630 & 2 & 0.38 & & & \\
\hline total & 237.82 & 8 & & & & \\
\hline
\end{tabular}

The Agiation speed is the most significant parameter with a $F$ value of 104.25 followed by $\mathrm{m} / \mathrm{o}$ ratio having $\mathrm{F}$ value of 67.46. The estimation of contribution factor (equation 3) of individual parameters also eludiciated the same results. Agitaion speed is the most influemcing parameter with a contribution facor of $33.55 \%$ for the conversion of FFA followed by ratio of $\mathrm{m} / \mathrm{o}$ with the contribution factor of $21.71 \%$. The concentration of the catalyst within the chosen span is found to be insignifant as infered by the ANOVA study and hence neglected in both the statistical analysis.

The correlation coefficient fo the esterificatipon reaction postulated by the ANOVA study. The statistical estimation of parameter $\mathrm{R}^{2}$ having value of 0.9968 implies the perfect depiction of experiemntal data in the model. The efficiency of the model can be viewed form the lower value of coefficient of variance (0.6991) and standard deviation (0.6177). The adequate precision value of 29.556 suggested the adequate signal of the model and hence model can be cosidered for the navigtion of the design space.

\subsection{Prediction of the regression model equation}

\subsubsection{Extraction of RBO}

Regression analysis could be done by following regression model equation given below. This equation can be developed by the result of ANOVA study and contribution factor. In this model equation, only four factors viz. extraction time $(\mathrm{min}), \mathrm{S} / \mathrm{R}$ ratio $(\mathrm{ml} / \mathrm{g})$, Power level (\%) and Size range (micron) had been considered by eliminating the least significant factor viz. Agitation speed (rpm) and sonication time (min). The physical significance of this model is that it can predict the oil yield at any chosen set of parametric conditions up to the given range of parameters. The high level factors are coded as +1 whereas low levels are coded as 1. The regression equation can predict the optimised parametric condition of the extraction process within the specified range of the parameters.

The regression equation is

OilYield $=18.35+0.0662 \mathrm{~A} 1[1]+0.1770 \mathrm{~A}[2]-$ $1.77 \mathrm{~A}[3]+1.03 \mathrm{~A}[4]+0.3500 \mathrm{C}[1]+1.65 \mathrm{C}[2]+1.49 \mathrm{C}[3]-$ $2.50 \mathrm{C}[4]-1.47 \mathrm{D}[1]-0.7480 \mathrm{D}[2]+1.99 \mathrm{D}[3]+0.7466 \mathrm{D}[4]-$ $2.53 \mathrm{~F}[1]+1.81 \mathrm{~F}[2]+0.0356 \mathrm{~F}[3]-0.2922 \mathrm{~F}[4]$

Residuals were defined to be the differences between the experimental responses (observed responses) and predicted responses. The predicted responses had been given by the model explained above. Careful examination of residuals could tell us the suitability of the model. Residuals were expected to be varied from 0 to certain constant values. The normal probability plot was an assessment of the normal distribution of data. Departure of points from the straight line indicated departure from normality. Fig 1 shows that the predicted value of the response has a good agreement form the actual response thus proved the suitability of the considered model. 

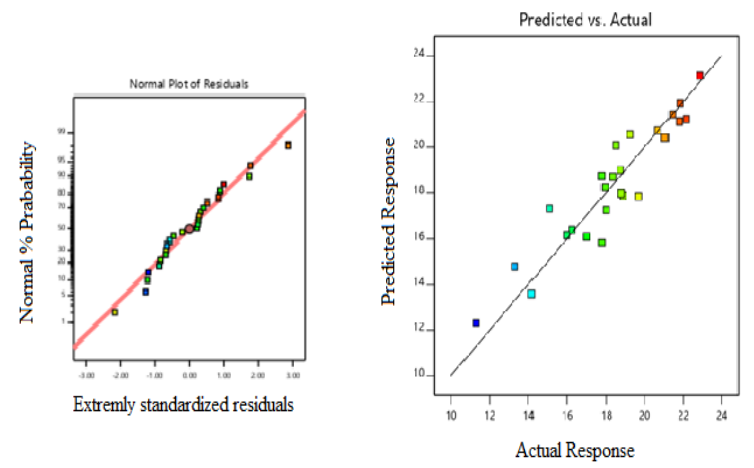

Fig. 1. Normal probability plot for experimental and predicted response (UAE Extraction)

\subsubsection{Esterification of oil}

The predicted regression equation of the model

FFA conversion $=+88.28-0.3233 \mathrm{~A}[1]+4.87 \mathrm{~A}[2]-$ $2.51 \mathrm{C}[1]+2.65 \mathrm{C}[2]-3.78 \mathrm{D}[1]-0.9967 \mathrm{D}[2]$

The comparison of the experiemntal data and predicted data are shown in Fig 2 and their close proximity inferred their accuracy.

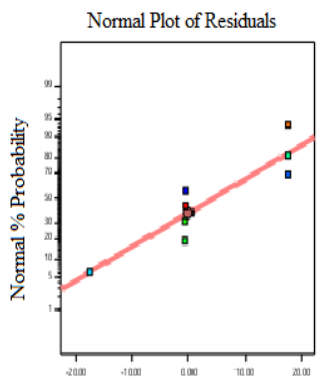

Extremly standardized residuals

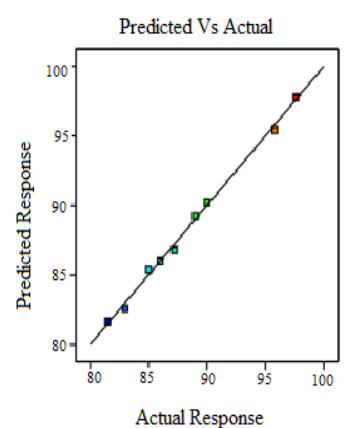

Actual Response
Fig. 2. Normal probability plot for experimental and predicted response (FFA conversion)

\subsection{Effect of process parameters}

\subsubsection{Extraction of RBO}

The effect of process parametrs viz. extraction time, power level, particle size and R/S are depicted in Fig. 3a to Fig. 3d respectively.As it can be visualised form the Fig. 3a that the rice bran oil yield showed to be increasing initially and after attainment of an optimal point, started decreasing. The highest yield is obtained about $16 \%$ at around $60 \mathrm{~min}$ of extraction time and can be considered as the favourable case in terms of high percentage of yield. In the initial period of extraction the driving force i.e. the concentration gradient between surface of the rice bran particles and bulk of the solvent was high and that attributed to the higher percentage of yield. But afterwards the driving force become weakens due to the enhancement of diffusivity resistance from the interior of the solid [14].
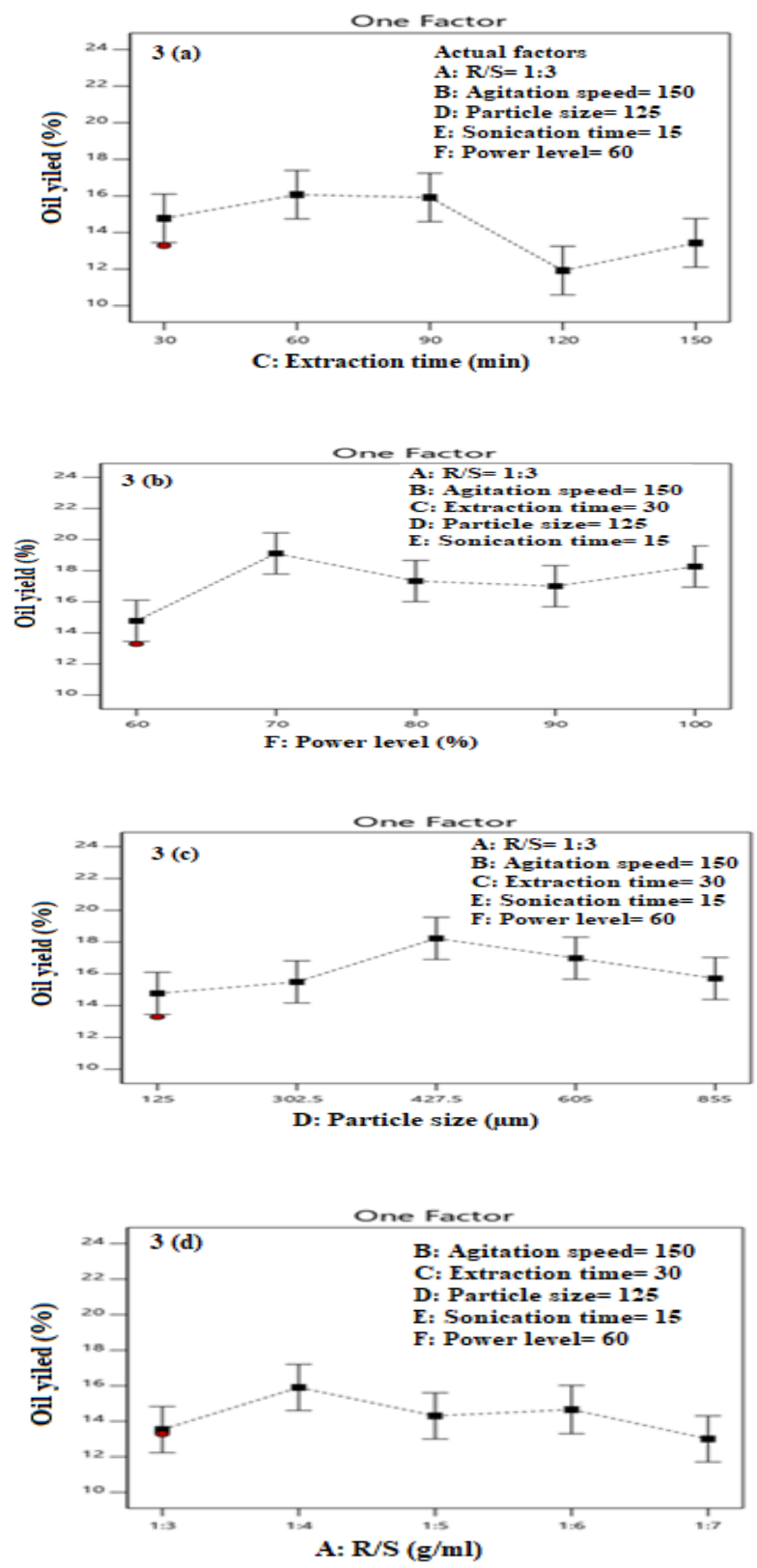

Fig. 3a. to 3d Oil yield vs Parameters

The effect of sonication power level on oil yield has been shown in Fig. 3b. It can be understood from the graph that oil yield has been increasing progressively with the increase in power level. A significant increase of $3.33 \%$ in oil yield was observed when output power level increased from 60 to 90 (1.5 times increases). This is due to the fact that as we increase the output power level, more amounts of bubbles was formed and collapsed resulted in releasing a higher amount of energy. Due to excessive temperature and pressure inside the bubble, bubbles got collapsed within a short span of time and releases large amount of energy. This attributes to the breakage of cell wall membranes which made it accessible to the contact of the solvent. The presence of firm cell walls might be the plausible reason for drop in 
oil yield at higher power level because the solvent couldn't be able to break these hard cell walls.

The effect of particle size of rice bran are depicted in Fig. 3c. Initially the trend of the grpah is found to be increasing with the increase in size of the bran particles and after attaing the maximum point the yiled showed downward trend with the increasing particle size. This peculiarity is mainly attributed by the fact that smaller size particles imparted greater interfacial area, due to which an increment in the oil yield was observed. Bigger particles imparted less amount of extraction yield because of the higher intra particle diffusion resistance. The highest yield of $18.2 \%$ (approximate) is observed at the particle size of $427.5 \mu \mathrm{m}$ can be regarded as the optimal point.

As shown in the Fig. 3d yields is increasing with solvent to rice bran ratio but after reaching an optimum point, started decreasing and became almost constant afterwards. The reason behind this kind of increment initially is that more amount of bran came into the contact of the solvent when the amount of solvent increased. After reaching an optimal point, the solvent has to go into the interior of the bran to extract the oil resulted in the decrement. Further increment would not affect much of the driving force between bran and solvent.

\subsubsection{Esterification of oil}

The esterification reaction were conducted according to the design array formulated by L9 orthogonalk matrix. The obtained experimental results were analysed to determine the effect of individual parametrs on the coversion of FFA. Agiation speed plays a vital role in the esterification reaction of high viscous oil. Hence for the higher conversion of FFA from the RBO agitation speed is found to be the most important parameter and illustrated in Fig. 3e. The maxium conversion obtained at $1000 \mathrm{rpm}, \mathrm{M} / \mathrm{O}$ ratio 8:1, catalyst loading $1.5 \mathrm{wt} \%$ and temperature of $50{ }^{\circ} \mathrm{C}$ was around $91 \%$. The higher agitaion speed produces turbulence in the reaction mixture which in turn increase the rate of reaction owing to the mimimisation of diffusional resistance and better mixing of the reactants.

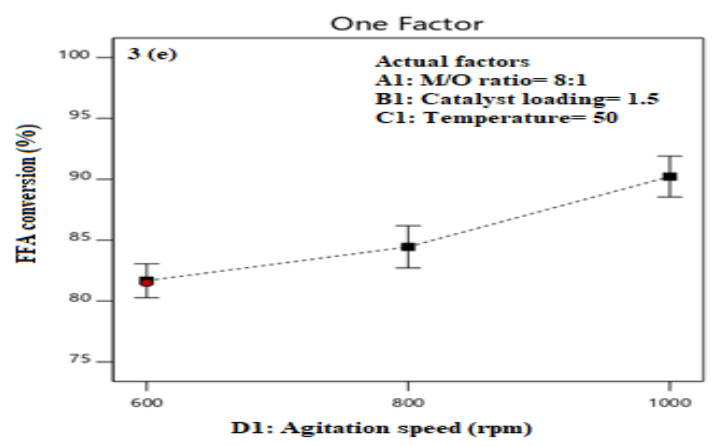

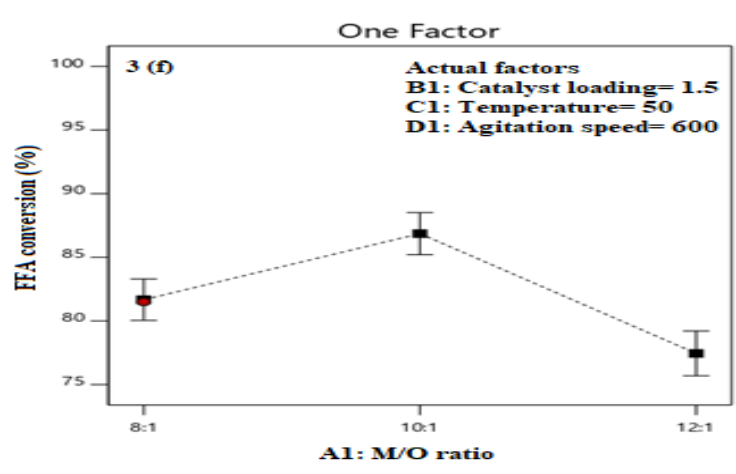

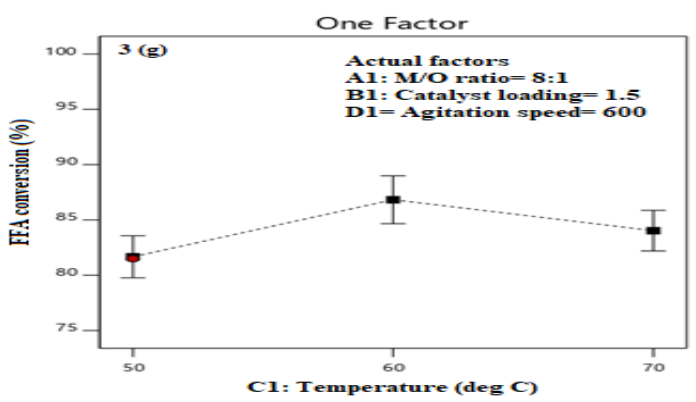

Fig. 3e. to 3g Effect of parameters on FFA conversion

The molar ratio of methanol to oil imparts an imporatnt role in the FFA conversion and illustrated in Fig. 3f. As it infers from the stoichiometry of the reaction that the higher amount of methanol is essential to shift the reaction towards the forward reaction i.e. the formation of esters. However, FFA conversion shows the decreasing trend after $\mathrm{M} / \mathrm{O}$ ratio of 10:1. This is because of the formation of high amount of water as the byproduct which imparts the decrese in lower conversion [28]. The reaction tenperature is varied at three levels in the experiment viz. 50,60 and $70{ }^{\circ} \mathrm{C}$. and their effect on the process are depicted in Fig. 3g. The maximum FFA conversion of around $87 \%$ is obtained at the reaction temperature of $60{ }^{\circ} \mathrm{C}$ while the other parametrs are remain fixed ( $\mathrm{M} / \mathrm{O}: 8: 1$; catalyst loading: $1.5 \mathrm{wt} \%$; agiation speed: $600 \mathrm{rpm}$ ). As it can be visualised, the increasing trend of the graph is due to the increase in reaction rate with the temperature. Also it is possible to maintain the constant molar ratio of methanol to oil within these chosen range of temperature by recycling the negligible evaporative loss of methanol. Further increse in the temperature shows decresing trend of FFA conversion.

\subsection{Fuel caharacterisation}

The acid value of the RBO exttracted by convetional soxhlet extraction was obatined as 22 whereas that pretreated by the ulttrasonic irradiation was found to be 5.7. This infers the fact that ultrasonic pretreatment saponifies the FFA content in the bran particles [23]. The fuel properties of the methyl esters of RBO were anlysed and illustrated in Table 8.

Table 8 The fuel properties of the methyl esters of RBO 


\begin{tabular}{|l|l|l|l|l|}
\hline Properties & $\begin{array}{l}\text { ASTM } \\
\text { limits }\end{array}$ & $\begin{array}{l}\text { Testing } \\
\text { procedure }\end{array}$ & Diesel & $\begin{array}{l}\text { Measured } \\
\text { Value }\end{array}$ \\
\hline Flash point & 130 & D93 & 68 & 165 \\
\hline Specific gravity & $0.8-0.9$ & D4052 & 0.85 & 0.87 \\
\hline K viscosity & $1.9-6$ & D445 & 2.6 & 5.31 \\
\hline Calorific value & - & D240 & 44.58 & 40.38 \\
\hline Acid value & 0.8 & D664 & - & 0.17 \\
\hline
\end{tabular}

The calorific value and specific gravity of the RBO based biodiesel is in good agreement with the mineral diesel. The ease of storage and transporation is emphasised by the thermal stability of the fuel characterised by the flash point determination which in the case of produced biodiesel found to be way higher than the diesel. Althogh the kinematic viscosity is observed to be higher than the diesel but still it is under permissible limit of ASTM standards.

\section{Conclusion}

In this work, the ultrasonic pre treated extraction of rice bran oil was carried out using hexane as the organic solvent. The process has been optimised using the L25 orthogonal array matrix formulated by Taguchi model and key factors affecting the yield were identified. The results stated that extraction time of $60 \mathrm{~min}$, ultrasonic power level of $70 \%$, particle size of $427.5 \mu \mathrm{m}$ and $\mathrm{R} / \mathrm{S}$ ratio of 1:4 were favourable conditions for the maximum yield of RBO. Among the six parametrs chosen extraction time is found to be the most significant parameter effecting the yield of RBO. Also it is established that the oil extracted using ultrasonic pre treatment had lower content of FFA in comapred to that extracted by the conventional solvent extraction. The secod part of the work constitutes the esterification of RBO using a homegoneous acid catalyst and study the process parameters using L9 orthogonal array matrix. The optmised condition predicted by the model is: Agitation speed $1000 \mathrm{rpm}, \mathrm{M} / \mathrm{O}$ ratio $10: 1$, reaction temperature $60{ }^{\circ} \mathrm{C}$ and catalyst concentration $1.5 \mathrm{wt} \%$. The statistical analysis demonstrated that agitation speed is the most significant parameter with a contribution factor of $33.55 \%$ followed by $\mathrm{M} / \mathrm{O}$ ratio $21.71 \%$ and reaction temperature $4.31 \%$. Regression model equation shows that the predicted value of the response had a good agreement form the actual response thus proved the suitability of the considered model. The fuel characteristics analysed by the ASTM methods are in close proximity with the mineral diesel.

\section{References}

1. F.Umbach, Energy Policy, 38, 1229-1240, (2010).

2. Z.Amini, et al., Energy Convers Manag, 141, 339-53, (2017).

3. A de Lima, C. Ronconi, C. Mota, Catal Sci Technol, 9, 2877-91, (2016).

4. M.G. Salinas-Juarez, P. Roquero, M. del Carmen Dur an-Domínguez-de, Bioelectrochemistry, 112, 145-152, (2016).

5. N. Chueluecha, A. Kaewchada, A. Jaree, Energy Convers. Manag., 141, 145-154, (2017).

6. M.S.H. Abdelfattah, O.S.M. Abu-Elyazeed, M.A. Abdelazeem, Energy, 143, 950-960, (2018).

7. F. Staat, E.Vallet, Chem Ind, 21, 856-63, (1994).

8. N. Kaur, A. Ali, RSC Adv, 5, 1328513295,(2015).

9. A. P. Bora, D. P. Gupta, K. S. Durbha, Fuel, 259 116262, (2020).

10. P. Verma, M.P. Sharma, Renew. Sust. Energ. Rev. 62, 1063-1071, (2016).

11. A.P Bora, S.H Dhawane, K Anupam, G.Halder Renew Energy, 121, 195-204, (2018).

12. L. Lin, D. Ying, S. Chaitep, S. Vittayapadung, Appl. Ener, 86, 681-688, (2009).

13. T.Narayana, B.Kaimal, S. R Vali, et al., E. J. Lipid Sci Technol, 104, 203-211, (2002).

14. M. Khoei, F. Chekin, Food Chemistry, 194, 503-507, (2016).

15. C. S Eskilsson, E.Bjorklund, J. Chromatography A, 902, 227-250, (2000).

16. B. Kaufmann, P. Christen, Phytochem Analysis, 13, 105-113, (2002).

17. H. Li, L. Pordesimo, J. Weiss. Food Res. Int., 37, 731-738, (2004).

18. J.Wu, L. Lin, F.T. Chau, Ultrason Sonochem, 8, 347-352, (2001).

19. G. Moradi, M. Mohadesi, Z. Hojabri, React. Kinet. Mech. Catal, 113, 169-186, (2014).

20. G. Baskar, A. Gurugulladevi, T. Nishanthini, R. Aiswarya, K. Tamilarasan, Renew. Energy, 103, 641-646, (2017).

21. A. Hajinezhad, S. Abedi, B. Ghobadian, Y. Noorollahi, Energy Convers. Manag, 99, 132-140, (2015).

22. M. Atapour, H.R. Kariminia, P.M. Moslehabadi, Process Saf. Environ. Protec, 92, 179-185, (2014).

23. Y. Zhang, M.A. Dube, D.D. McLean, M. Kates, Bioresour.Technol, 89, 1-16, (2003).

24. C. Lai, S, Zullaikah, S.R Vali, J. Yi.-Hs., 2005. J. Chem. Technol. Biotechnol, 80, 331-337, (2005).

25. K. Srilatha, R. Sree, B. Devi,P. Prasad, R. Prasad, N. Lingaiah, Bioresource Technology, 116, 53-57, (2012). 
26. S.H. Dhawane, A. P. Bora, T. Kumar, G. Halder. Renew Energy, 105, 616-624, (2017).

27. EN 14104:2003. Fat and oil derivates. Fatty Acid Methyl Esters (FAME). Determination of acid value.

28. A., M. Faiz, R. Yunus, G. Mohd. et al., Int J Eng Technol, 5, 92-98, (2008). 